\title{
AUTORIDAD, POESISTOCRACIA Y ARBITRAJE: HAROLD BLOOM, LECTOR DEL QUIJOTE
}

\author{
Julián JIMÉNEZ HEFFERNAN \\ Universidad de Córdoba \\ jsjimenez@uco.es
}

Das Tun ist alles.

Nietzsche ${ }^{1}$

lo primero que hizo fue limpiar unas armas»(Cervantes 1605: 41). Así
empieza la acción (hizo) cuyo relato es el Quijote. De ahí la comunidad de
arranque y de intención con un precursor decisivo, la Gerusalemme liberata, en la que Tasso canta «le arme pietose e 'l capitano / che'l gran sepolcro liberò di Cristo» (I.1; 1581a: 4). La ambición del hidalgo, más modesta, es liberar cautivas y cautivos, deshacer, en suma, todo género de agravios y resolver aquellos lances en los que acierte a ponerse o colocarse. Nótese la formulación: «deshaciendo todo género de agravio y poniéndose en ocasiones y peligros donde, acabándolos, cobrase eterno nombre y fama» (41). La misión de Quijano, pues, como la del tropo para Nietzsche, es sich setzen, ponerse en ocasión o en caso: situarse armado en calidad de caballero para dar lugar -como el inerme Lázaro algunas décadas antes- a un caso ${ }^{2}$. Aseguraba Nabokov que «all poetry is positional» (1967: 169). Y así el Quijote es un poner, un hidalgo dis-puesto, una cosa que se pone frente a todos los enemigos potenciales, incluida toda especie de genio maligno. De igual manera, el condottiero Goffredo di Buglione en el poema de Tasso hizo mucho («molto egli oprò co 'l senno e con la mano») en su ponerse para vencer una oposición de fuerzas reales y sobrenaturales («e in van l'Inferno vi s'oppose...», Gerusalemme I.1). Posición, exposición, oposición: he ahí el destino existencial del héroe, el mapa categorial que dibuja su vivencia.

\footnotetext{
1 "La acción lo es todo" (Zur Genealogie der Moral 1.13)

2 Para la comprensión posicional del tropo en Nietzsche, véase Paul de Man (1979: 118-26). La centralidad del caso en el Lazarillo ha sido estudiada por Juan Carlos Rodríguez (1994: 149-201).
} 
Pues todo el misterio se condensa ahí, en ese primer hacer que fue limpiar unas armas. ¿Cómo es posible que un hidalgo empobrecido se levante, una mañana, y decida limpiar las armas de sus bisabuelos? Todo lo que sucede después, desde la primera salida armado -«se armó de todas sus armas [...] tomó su lanza y por la puerta falsa de un corral salió al campo» (41) - hasta su muerte, es un efecto de la inercia de esa primera acción incomprensible, de «lo primero que hizo». Comenzar (limpiar, armar, salir), en mecánica, es siempre lo que más cuesta. Todo el que ha visto despegar un helicóptero o emerger casi entera del agua a una nadadora sincronizada entiende lo que digo. Pasar de la quietud a la moción exige ya un origen externo de energía cinética (una colisión) ya una impulsión de energía interior. El resto es pura mecánica heroica, escuetamente formulada por Gracián: «Todo móvil instable tiene aumento y declinación» (1637: 71). Es evidente que en esta disyuntiva se la juega la dialéctica entre determinismo social (vigente, críticamente, desde la picaresca hasta el naturalismo) y auto-determinación individual (reactivada decisivamente por Schiller con su idea proto-romántica de la Selbstbestimmung). La crítica cervantina suele soslayar este asunto decisivo de la primera acción alegando los motivos de enajenación libresca que aduce el narrador. Al describir al hidalgo como un «longe graphisme maigre comme une lettre» que «vient d'échapper tout droit du bâilement des livres» (1966: 60), Michel Foucault agrava con lucidez el signo de esta preterición. No es cierto que todo el ser del hidalgo se reduzca a «language, texte, feuillets imprimés, histoire dejà transcrite» (60). $\mathrm{Y}$ es que, como bien recordaba Martín de Riquer en un librito memorable, no todo es literatura:

\footnotetext{
Pero también serían inexplicables novelas como el Tirant lo Blanch, el Curial e Güelfa o el Jehan de Saintré si no hubiesen existido caballeros andantes de carne y hueso, que vagaron por Europa en demanda de aventuras. Don Quijote los aducía como un sólido argumento a su favor en sus fantasías. Fernando del Pulgar, en sus Claros varones de Castilla, había hecho mención de algunos de ellos... Un siglo después, estos nombres y otros parecidos volverán a sonar en empresas similares. No serán empresas en Borgoña, Inglaterra, Alemania, Italia, Constantinopla, o el mar Negro, sino en Méjico, Perú, Chile, el mar del Sur, etcétera. Sin nuestros caballeros andantes del siglo XV difícilmente hubieran existido los conquistadores de Indias, tan dados también a la lectura de libros de caballerías. Don Quijote, como estaba loco, siguió el itinerario que podía llevar a una empresas en su siglo ya caducadas: si hubiese estado sano hubiera hecho lo mismo que tantos otros contemporáneos suyos: desde la Mancha dirigirse a Sevilla, y de allí embarcarse para Indias, donde era mucho más factible que en Puerto Lápice «meter las manos hasta los codos en esto que llaman aventuras» (1967: 160).
}

El argumento de Riquer invoca, a su vez, un vicio lógico, una petición de principio que en la exégesis cervantina adopta la forma de la falacia, denunciada por Spinoza, de las causas finales: «como estaba loco». ¿Estaba ya realmente loco o comienza su locura cuando limpia las armas y sale al campo? ¿Acaso no cabe interpretar su locura como un diagnóstico retrospectivamente proyectado sobre unas acciones incomprensibles? Por otro lado, jamás podría un envejecido y empobrecido 
hidalgo embarcarse a América en calidad de nada: la solución que sugiere Riquer es sencillamente inviable. Si el hidalgo pretende actuar, como actuaron caballeros reales e imaginarios, sólo lo puede hacer en suelo peninsular, preferiblemente próximo a su tierra. Pero no es esto lo que nos concierne. Lo que interesa destacar del argumento de Riquer es la constatación de una circulación real de energía heroica en el cuatrocientos hispano en suelo peninsular, así como la reconducción literaria de dicha energía en el relato caballeresco y su conmutación o transformación histórica en la energía que dinamizó la épica, más o menos improbable, aunque penosamente real, de la conquista de América. Riquer insiste con perspicacia en la determinación recíproca entre realidad y fantasía caballeresca, pero conviene subrayar que la desconstrucción irónica de la fantasía caballeresca (la novela Don Quijote de la Mancha) no es una fantasía realista sólo por el hecho de de que descubre una realidad lingüística y socio-histórica velada por la penumbra estetizante del romance, sino también porque restituye el hecho real del caballero andante atrapado en su voto o empresa. El hidalgo no es un grafismo escapado de un libro, sino un anacronismo liberado del pasado. Que el pasado y cierto presente español (la conquista de América, las guerras contra los moriscos) tuviera en sí consistencia libresca, es decir, una investidura fantástica de naturaleza heroica, es otro problema. Y ello no justifica de ningún modo la oclusión de la energía heroica real que alienta en el Quijote, hasta el punto de ponerlo en marcha. Tampoco es posible argumentar, como hace el crítico Marziano Guiglielminetti, que ni la batalla de Lepanto ni ningún otro asunto contemporáneo (la victoria turca en Hungría, las guerras de religión en Francia) dejaron huellas en la escritura de Tasso ${ }^{3}$. Tanto el Quijote como la Gerusalemme están penetrados de una fuerza arcaica, de una violencia primitiva, denunciada por Simone Weil en su lectura de la Ilíada como «poema de la fuerza», que la cultura occidental decodifica discontinuamente como heroica, y es dicha energía la que pone en movimiento sus acciones respectivas ${ }^{4}$. El clasicismo es, entre otras cosas, el segmento temporal en el que la violencia militar es unilateralmente interpretada como heroica. En ese sentido preciso, la Edad Media cristiana es clásica. Cuando durante el siglo XVII la guerra se convierte en un sucio avatar de funcionarios, mercenarios e ingenieros, el clasicismo se descompone. De Don Quijote a West Side Story, la bravuconería latina reside en y es residuo de este clasicismo heroico, una matriz cultural que encuentra en el valentón del soneto cervantino -heredero del miles gloriosus- su expresión más contundente. Pero el caso es que, a diferencia del valentón, cuya postura queda en nada, don Quijote se pone y expone con una obstinación que invita al desafío

\footnotetext{
${ }^{3}$ Véase su «Introduzione» a Torquato Tasso, Gerusalemme liberata (apud Tasso, 1581a: 24).

${ }^{4}$ Harold Bloom discrepa de la interpretación de Weil en su lección «From Homer to Dante», recogida en Ruin the Sacred Truths (1987: 28-29).
} 
de la contra-posición. E insisto en la pregunta: ¿de dónde procede la energía, la fuerza, de dicha posición?

En un riguroso estudio reciente, Anthony Cascardy (2012) trata de descifrar la dimensión política de la novela de Cervantes. Para el crítico norteamericano, cabría ver en el hidalgo a un arbitrista camuflado, y en su insensato afán de ayudar a la república, una suerte de remedio que Cervantes construye irónicamente con el fin de trasladar al lector, mediante una sofisticada rotación imaginativa, un buen puñado de lecciones de moralidad civil y cívica. La lectura de Cascardy es sugerente, pero se despliega en un aislamiento intolerable del texto cervantino: si el Quijote es novedoso porque propone una regeneración política entonces dicha novedad debe de leerse no tanto en comparación con otros textos políticos anteriores y contemporáneos (Platón, Aristóteles, Cicerón, Maquiavelo, humanistas renacentistas, juristas escolásticos) como en confrontación con otros textos literarios (Amadís, Abencerraje, Diana, Carcel de Amor, Lazarillo, Guzmán...) que potencialmente también podrían alojar un mensaje político ${ }^{5}$. Lo novedoso del Quijote no es que proponga una revisión de las bases morales de la comunidad política atendiendo a la relación conflictiva entre teoría y práctica, letras y armas, palabras y lanzas, sino más bien que narre la historia absurda de un sujeto que diserta y dialoga efectivamente mucho, pero que también sale, se pone, pega y golpea de manera radicalmente insólita. El Quijote no es una pro-puesta conceptual, sino una puesta o posición existencial, cimentada en la autoridad inmemorial de la violencia. Cascardy sugiere que el concepto quijotesco de justicia se yergue frente a la regulación institucional de principios jurídicos dirigidos a legitimar el uso de la fuerza. De ahí el desafío que dicha justicia supone respecto de la «autoridad» absoluta del estado (Cascardy 2012: 25). También Bloom subraya que la violencia como mecanismo para acceder a la gloria es presentada por Cervantes como un absurdo (1994: 135). Discrepo de ambas opiniones, pues la autorización personal de la violencia parece un componente determinante de la posición-Quijote. Es evidente que ciertas recetas platónicas y ciceronianas pudieron alimentar el republicanismo utópico de Cervantes, pudieron, en definitiva, determinar su propuesta de dialógico y virtuoso comunitarismo cívico, pero ¿qué fuentes de energía motivaron la posición de su personaje, armado, en medio del campo? Por otro lado, la interpretación normativa de la locura del personaje, fomentada

\footnotetext{
${ }^{5}$ El heroísmo político de Don Quijote se cifra, pues, no sólo en su condición de arbitrista, sino también en su condición de árbitro. Resulta sintomático, en este sentido, el desprecio paralelo de Quevedo hacia el arbitrio y hacia el «loco repúblico» (106) en El Buscón (II.1) su profunda incomprensión tanto de la locura como de la mala poesía en la «Premática del desengaño» (Buscón, II.3). Cervantes, en cambio, sentía una piedad inmediata hacia ambas indigencias. Es en este tipo de contraste donde resplandece la originalidad cervantina, el signo de su irónica ternura. Posiblemente, y pese a las tentaciones platónicas que pudieran asediarle, Cervantes habría suscrito el siguiente axioma enunciado por dos pensadores decisivos del post-marxismo contemporáneo: «Every radical democratic politics should avoid the two extremes represented by the totalitarian myth of the Ideal City, and the positive pragmatism of reformists without a project» (Laclau \& Mouffe, 1985: 190).
} 
por el narrador, en clave de enajenación libresca, convierte a don Quijote en una mera res-puesta, en un trozo de texto que se escapa de otro o que responde a otro, cuando en realidad lo que en el relato rompe la inercia de la quietud no es la lectura, sino la pose, aparente, primero, de limpiar las armas, y la posición, finalmente, armado en medio del campo. Hubo muchos que leyeron pero no salieron. El problema del hidalgo no es la indigestión de lecturas, sino la salida al campo. De la inmovilidad a la moción: ese es el misterio. Y lo primero que hizo, después de años y décadas de no hacer nada, o nada más que sobrevivir a una inercia doméstica de caza y ocio, almuerzos escasos y lecturas abundantes, fue limpiar las armas... Quijano pasa a ser Quijote y comienza la novela.

En la lógica deliberadamente forzada del argumento que vengo esbozando, y que reduce provisionalmente las posibilidades interpretativas de la novela al signo de su puesta (existencial), propuesta (moral-política) o respuesta (metaliteraria), sería previsible suponer que Harold Bloom, un crítico obsesionado por la naturaleza metaliteraria del texto literario, un crítico que escribió en una ocasión que «the meaning of a poem can only be another poem» (1973: 95), optaría por la tercera de estas vías exegéticas, pero no es así. La lectura que Bloom hizo del Quijote en The Western Canon (1994) se presenta como una defensa de la opción existencial del héroe cervantino, un individualismo secular y heroico que, lejos de constituir una expresión de locura sobrevenida, debe concebirse como la decisión, voluntariamente tomada por el personaje, de ingresar en un juego. Uno de los rasgos distintivos del juego cervantino se cifraría en el modo en que hace posible un espacio dialógico de amistad desinteresada. Ahí habría de situarse la contribución cognitivo-moral central de Cervantes como «wisdom writer» a la modernidad, que somos en la medida en que toleramos nuestra extravagancia en un errar dialógico en torno a las bases mismas del juego:

The loving, frequently irascible relationship between Quixote and Sancho is the greatness of the book, more even that the gusto of its representations of natural and social realities. What unites the Don and his squire is both their mutual participation in what has been called 'the order of play' and their equally mutual if rather grumpy affection for each other. I cannot think of a comparable friendship anywhere else in Western literature [...] Don Quixote is neither a madman nor a fool, but someone who plays at being a knighterrant. Play is a voluntary activity, unlike madness and foolishness. Play, according to Huizinga, has four principal characteristics: freedom, disinterestedness, excludedness, or limitedness, and order [...] The Don lifts himself into ideal place and time and is faithful to his own freedom, to its disinterestedness and seclusion, and to its limits, until at last he is defeated, abandons the game, returns to 'Christian' sanity, and so dies (Bloom, 1994: 13132).

Este fragmento condensa el meollo de la tesis de Bloom, y adelanta con elocuencia el signo romántico de su lectura. Que don Quijote no es ni un idiota ni un loco quiere decir que no es víctima de ningún determinismo, ni somático, ni social ni cultural. Don Quijote, según Bloom, es el resultado de la auto-determinación voluntaria 
de Alonso Quijano. Ahora bien, esta Selbstbestimmung no es una mera self-fashioning en sentido neo-historicista que da al término Stephen Greenblatt -una reconducción propia de energías sociales existentes, una readaptación personal de vocabularios disponibles- pues ello implicaría ceder a la lógica determinista. Para Bloom lo importante no es tanto que Alonso Quijano escoja el disfraz (culturalmente disponible) de caballero, sino que tout court escoja, es decir, que pueda efectivamente «elevarse a un tiempo y espacio ideales» de acuerdo con su propia voluntad. Regresamos con ello al enigma del movimiento espontáneo: ¿cómo se auto-eleva un cuerpo desde la quietud? ¿qué reservas de energía se acumulan en qué depósitos de la voluntad para permitir esa cosa tan profundamente enigmática que Bloom llama «acción voluntaria»? Por otro lado: ¿con qué fin actúa el hidalgo? Bloom insiste, siguiendo a Huizinga, en el mero interés desinteresado del juego, pero esto resulta incompatible con su alusión, algunas páginas después, a la idea, expuesta por Unamuno y sin duda correcta, de que el motivo del hidalgo no es otro que la «eternal fame»: «una expansión de la personalidad en el espacio y el tiempo» (citado por Bloom, 1994: 137). En rigor, la capacidad de desinterés (disinterestedness) que Bloom no cesa de identificar en Shakespeare y que en este capítulo atribuye también al personaje cervantino es un rasgo moral mucho más rastreable en Fénelon que en Cervantes. La educación política de Télémaque (1699) contiene un elemento de domesticación cultural desinteresada que es del todo ajeno al belicismo agreste e impulsivo del hidalgo, una propensión a la violencia inscriptora que está siempre, en Cervantes, al servicio de la inmortalidad. El cristianismo asimilado de Fénelon le permitía desplazar la inmortalidad a un espacio escatológico, algo que para Cervantes era, como veremos, del todo inconcebible.

La lectura de Bloom aborda, asimismo, otros asuntos como la diferencia entre picaresca y novela, el efecto de la ironía y los temas relacionados de la gloria, el heroísmo, la perseverancia, la supervivencia, la indestructibilidad y la autoridad. El primero de estos asuntos es clave, pues devuelve la argumentación a espacios exclusivamente literarios o, mejor dicho, metaliterarios. Por una parte, en su afán por matizar la tesis de la locura, Bloom concede al menos que dicha locura existe, pero matiza que se trata de un ejercicio calculado, una estrategia poética (poetic strategy) o locura literaria (literary madness):

What does madness mean if its sufferer cannot be deceived by other men or women? No one exploits Don Quixote, not even Quixote himself. He takes windmills for giants and puppet shows for realities, but he is not to be mocked, because he will outwit you. His madness is a literary madness [...] Don Quixote is mad because his great prototype, the Orlando (Roland) of Ariosto's Orlando Furioso, fell into erotic madness ... [Don Quixote] wants to win, no matter how many times he gets painfully flattened. His madness, as he makes clear, is a poetic strategy worked out by others before him, and he is nothing if not a traditionalist (Bloom, 1994: 135). 
Como apuntaba antes, resulta sorprendente que Bloom renuncie en este punto de su argumento a escrutar con algo más de atención al conjunto de deudas literarias que el texto cervantino contrae con la tradición caballeresca del quinientos, no sólo con el poema de Ariosto. Ello le permitiría ejercitar su mecanismo de lectura intertextual anomalista, persiguiendo el régimen de apropiaciones y desvíos tropológicos que contribuyen a perfilar la posición, postura o pose (stance, es el término usado por Bloom) del Quijote: el hidalgo como una bola de billar que sale despedida tras un puñado de carambolas figurales cuyas trayectorias conviene desentrañar. Después de todo, «criticism is the art of knowing the hidden roads that go from poem to poem» (1973: 96). Pero lo cierto es que Bloom no acostumbra a leer el texto narrativo con las lentes de su teoría poética. En rigor, no le hace falta, pues el texto narrativo constituye la explicitación de la trama psicológica que, de acuerdo con su teoría poética, subyace a la mecánica anomalista de los tropos. Es decir, la novela hace visible aquello (la ambición personal) que en la poesía queda alegóricamente codificado como conflictiva dinámica figural. Mientras que en el poema un yo no puede literalmente confesar su más o menos inconsciente agonía emocional -decir «tengo miedo», «siento deseo, odio, envidia», «quiero ser más y tener más poder»- la novela existe para proporcionar curso y discurso a dichas inclinaciones psicológicas. De ahí que para Bloom toda novela sea drama psicológico y todo poema cripto-drama psicológico. Y en el fondo, novela y poema, no sean más que drama, teatro, escenificación, despliegue, pliegue y repliegue de troposiciones pronominales. En el fondo, la tesis del teólogo judío Martin Buber sobre las matrices relacionales I-Thou y I-It que Harold Bloom empleó en su primera monografía sobre Shelley (1959: 1-10) no ha dejado nunca de condicionar su concepción dinámica del texto literario como escenificación de un drama pronominalidentitario. Conviene, en cualquier caso, subrayar una cuestión: para Bloom las personas no deben ser tropos, aunque los tropos, en tanto que posiciones pronominales, sean casi personas. Y las personas no deben ser tropos especialmente desde que el crítico norteamericano hiciese suya la cruzada contra el determinismo materialista de ciertas trincheras académicas (neo-historicismo, feminismo, estudios culturales...) por mucho que, en sus escritos más radicales de los años setenta su concepción de la dinámica tropológica estuviese poderosamente marcada por el determinismo freudiano. Así, para el Bloom de 1994, el hidalgo manchego debe de ser algo más que el rendimiento de una dinámica intertextual, algo más que un grafismo fugado de su párrafo. De ahí la aparentemente insólita distancia que su ensayo toma respecto de la lectura meta-literaria del Quijote.

Bloom no niega que haya, en el hidalgo, deseo mimético, como postula Girard en un ensayo clásico, lo que niega es que la dialéctica de la emulación (aquello que se desea) sea más importante que el deseo. De ahí también la distancia que adopta respecto 
de la potencial asimilación genérica del Quijote en la convención narrativa picaresca. Bloom se apoya en las ideas de su colega y amigo Roberto González Echevarría para insistir en el desmantelamiento irónico que Cervantes realiza de la tradición picaresca, y luego refiere de forma algo vaga a la tradición crítica que ve en la novela cervantina una novedosa y fundacional superación genérica de la picaresca: «Since Cervantes' remarkable experiment is credited by many as having invented the novel, as opposed to the picaresque narrative, the devotion of so many novelists is understandable enough» (Bloom, 1994: 130). Y más adelante: «Critics generally agree that the contrast between Ginés and the Don, picaroon trickster and chivalric visionary, is partly an opposition of two literary genres, the picaresque and the novel, which Cervantes essentially invented» (141). Evidentemente, Bloom se limita aquí a sobrevolar un espinosísimo problema crítico, que está todavía hoy muy lejos de haber sido resuelto. No entraremos en él, pero sí conviene al menos sondear las razones que presumiblemente le indujeron a soslayar este asunto de un plumazo tan ambiguamente contundente: «is credited [...] as having invented», «critics generally agree», «essentially invented». ¿Se lo cree realmente o se limita a consignar maliciosamente un rumor? Lo ignoro. Mi sospecha es que se limita a tolerar esta tesis con fines estratégicos. Ello le evita tener que habérselas con la otra tradición narrativa que, junto a la del romance caballeresco en prosa, pudo determinar el hapax -pace Pierre Menard- que llamamos Quijote. Le evita, entre otras cosas, tener que dar cuenta de la decisiva relación que existe entre el Quijote y el Guzmán de Alfarache. Pues ¿dónde está el Guzmán en la lectura de Bloom? En ningún sitio. Y es que para Bloom es totalmente inaceptable reconocer la potencial paternidad picaresca de una criatura, como el hidalgo, que a su juicio solo significa en tanto que «chivalric visionary». Ciertamente, la tradición picaresca nada tiene que ver con la energía visionaria, a menos que optemos por leer (y no es imposible) la Vida de Santa Teresa como una fantasía visionaria que persigue camuflar (legitimar y sublimar) una estricta relación picaresca. Como demuestra el propio Cervantes en El rufián dichoso, la distancia entre cielo y suelo es mucho más insignificante de lo que la insania eróticomístico-heroica de nuestras letras áureas estaría dispuesta a tolerar -a tolerar, es decir, para lograr mantener al loco/a en juego o al pronombre en posición-. Para el Quijote, como para Santa Teresa, el único fin aceptable del juego (el ominoso Game Over) coincide con la muerte.

Describir al hidalgo como «chivalric visionary» es suficientemente revelador de unas cartas hermenéuticas que Bloom nunca oculta. El hecho de que Unamuno se torne, en su ensayo, en una referencia de autoridad acredita el signo ultra-romántico de la interpretación bloomeana: 
Unamuno called him, a Kafkan before Kafka, because his madness comes from a faith in what Kafka was to name 'indestructibility'. Unamuno's Knight of the Sorrowful Countenance is a quester for survival, whose only madness is a crusade against death (Bloom, 1994: 129).

Ahora bien, del heroísmo cristiano de Unamuno, a Bloom le interesa más el heroísmo que lo cristiano. Le interesa el componente épico-heroico implícito en toda búsqueda, también anti-cristiana, pero especialmente pagana, de inmortalidad:

Romantics (myself included) see Quixote as hero, not fool; decline to read the book primarily as satire; and find in the work a metaphysical or visionary attitude regarding the Don's quest that makes Cervantine influence upon Moby Dick seem wholly natural (130).

En línea con esta lectura romántica, Bloom cifra todo el valor de la novela cervantina en «its revelation and celebration and celebration of heroic individuality» (130). La ambición de este individualismo heroico asigna una orientación precisa al juego que la novela presumiblemente despliega: Don Quijote desea, por encima de todo, ganar -«he wants to win» (135)-. Lo que confiere singularidad al heroísmo quijotesco -Bloom habla de «shocking heroism» (136)- no es ni su epigonalidad libresca ni su improbabilidad ontológica, sino más bien la mera energía, la fuerza innegociable de su persistencia. Y es precisamente esta «heroic persistence» (144) la que convierte al hidalgo en un poeta de la acción («a poet of action»):

Unamuno's Quixote is a paradoxical agonist, the ancestor of the diminished questers who wander through our chaos in Kafka and Beckett. The hero of a secular 'indestructibility' was perhaps unintended by Cervantes himself, but he achives apotheosis in Unamuno's fiery commentary (138).

Como vemos, la apropiación estratégica de la lectura romántica que Unamuno hace del Quijote determina totalmente la interpretación de Bloom. Pero conviene subrayar una cuestión esencial: pese al desinterés por la dimensión meta-literaria del Quijote, al plantear esta lectura, el crítico norteamericano no se distancia en absoluto de las rutinas tropológicas que orientaron sus primeras lecturas de poesía anglo-americana. Esto resulta particularmente apreciable en la determinación de dos conceptos decisivos: fuerza y errancia.

Para Bloom -como para Nietzsche, Freud y Marx- todo el problema hermenéutico se cifra en el enigma del origen de la fuerza o energía. Si el estructuralismo se conformó con inventariar los protocolos de orden que administran, en un plano semiótico, el reparto diferencial de una energía ya existente, a ciertos pensadores post-estructuralistas les intrigó el origen de dicha energía. En un célebre ensayo de 1963, titulado «Force et signification», Jacques Derrida recordaba que la horizontalidad reclamada por el estructuralismo estaba siempre amenazada por la verticalidad de la fuerza: 
Autoridad, poesistocracia y arbitraje: Harold Bloom, lector del "Quijote"

Dans cet exigence du plat et de l'horizontal, c'est bien la richesse, l'implication du volume qui est intolérable au structuralisme, tout ce qui de la signification ne peut être étalé dans la simultanéité d'une forme. Mais est-ce un hasard si le livre est d'abord volume? Et si le sens du sens (au sens général de sens et non de signalisation) c'est l'implication infinie? Le renvoi indéfini de signifiant à signifiant? Si sa force est une certaine équivocité pure et infinie ne laissant aucun répit, aucun repos au sens signifié, l'engageant, en sa propre économie, à faire signe encore et à différer? (Derrida, 1967: 42).

Por decirlo con Foucault contra Foucault, si el hidalgo es un grafismo que escapa de un libro ello implica, necesariamente, la erupción de un volumen dinámico en el plano geométrico del libro, y dicho volumen sólo puede justificarse si admitimos que la horizontalidad del libro (el plano de representación Amadis o Sergas) está ya necesariamente, inherentemente, constitutivamente, convulsionado por una fuerza que el texto precariamente retiene. Nabokov estaba equivocado: resulta imposible leer el Quijote como una partida de ajedrez (Nabokov, 1941: 89-112), a menos que uno esté dispuesto (y el narrador ruso no lo estaba) a interrogar la fuerza que pone en movimiento las piezas. E insisto: el único interés de Bloom desde finales de los cincuenta hasta el presente es averiguar el motivo de la moción, es decir, la moción de la moción, la energía que pone en movimiento a las figuras de la literatura: «Y lo primero que hizo fue limpiar unas armas». Pese a su progresiva desafiliación del paradigma desconstructivo, lo cierto es que el Bloom de los sesenta y setenta compartía dicho interés con pensadores como Derrida y de Man, a quienes le unían algo más que lazos de amistad y admiración. Con el pensador francés compartía una curiosidad insaciable por sondear la violencia de la metafísica, aquello que de inscripción catastrófica y eruptiva tenían los tropos institutores de toda mitología blanca o discurso ideológico, incluido el religioso y literario. El enigma no es el tropo (en un mundo torcido, lo torcido no sorprende), sino la institución del tropo, la fuerza que lo posiciona en el plano-discurso dando origen y carta de naturaleza a la errancia y la distorsión (resulta curioso el desinterés de la teoría política por el defecto humano que hizo necesaria la política, y el de la teología por el origen del pecado que hizo necesaria la religión). Con de Man, Bloom compartía la certeza de que en Nietzsche cabía encontrar algo así como una respuesta para este enigma -balístico y dionisiaco, orgánico y militar- del posicionamiento verbal: ¿cómo es posible decir desde el silencio?, ¿qué fuerza autoriza esa emisión de voz y de sentido?, ¿y qué perversa inflexión de dicha fuerza transmuta la postura en impostura?

Quizás el libro en el que Harold Bloom ha explorado con más obstinación el problema de la fuerza sea Agon: A Theory of Revisionism (1982), el estudio que cierra la serie de intervenciones teóricas iniciada con The Anxiety of Influence: A Theory of Poetry (1973), y continuada con A Map of Misreading (1975). Recordemos, que para el Bloom de 1994, Don Quijote es algo más que un visionario: es un agonista, un actor (poeta de la acción) que se pone deliberadamente en juego en un drama de identidad y 
supervivencia. En el segundo ensayo del libro, titulado «Agon: Revisionism and Critical Personality», Bloom ofrece tres respuestas posibles al enigma del arranque del sentido, «how meaning gets started»:

I have three answers, two of which at least are incompatible, and all of which turn upon usurpation, upon violence, because contra Foucault the human mind cannot conceive of interpretive power without the king. Interpretation is implicitly hierarchical, and cannot proceed without usurpation of authority. Meaning gets started by a catastrophe that is also a ruining and breaking creation -originally a Gnostic formulation. Or else meaning gets started by a transference of a purely fictive earlier authority to a later representative -originally a Hebraic formulation. Or else meaning gets started by an act of violence, textual or physical, in a family grouping -originally what Vico called a Gentile formulation, both Asiatic and Greek (Bloom, 1982b: 43).

Las tres respuestas postulan una violenta usurpación de autoridad, aunque sólo la segunda invitaría al historicismo literario y metaliterario: el Quijote como repetición o transferencia de Tancredi, Orlando, Amadís... o del Guzmán. La tercera se sitúa en el terreno de un historicismo secular, propiciado por Vico, que Edward Said solicitó para su hermenéutica narrativa en un estudio, profundamente desconstructivo, sintomáticamente titulado Beginnings (1975: 1-95). La primera, finalmente, presume un creacionismo catastrófico compatible con las lecturas gnósticas que Bloom hizo del romanticismo inglés. De ahí, sin duda, la inclinación del crítico norteamericano hacia esta tercera respuesta en su lectura, doce años después, del Quijote: el hidalgo estalla desde la nada, dibuja en el aire una silueta identitaria, persiste agónicamente en dicha silueta, y se desvanece nuevamente en el vacío. O en la memoria.

El otro aspecto decididamente pre-desconstructivo de la existencia quijotesca es precisamente la extra-vagancia de dicha silueta, la errancia de dicha (triste) figura. Caballero errante o knight-errant: cuando Bloom invoca este tipo literario, se limita en realidad a sobre-escribir el rasgo determinante, desde Nietzsche, Fontane y Heidegger de la dinámica existencial-narrativo-tropológica: irren, Irrungen, Wirrungen. Estamos, de nuevo, ante el régimen de la «certaine équivocité» que Derrida asignaba a los dominios de la fuerza. La fuerza vertical se transmuta, topológica y tropológicamente, en errancia horizontal, forzando a toda figura, triste o gaya, à différer. En un ensayo titulado «Keats: Romance Revised», Bloom asegura que «a poem is a kind of error» (1976: 131), una afirmación que cabría abstraer de su contexto exegético si no fuese porque el «romance» que Keats revisa (no olvidemos que el Quijote se lee como revisión del romance en el sentido amplio de narración heroica en prosa o verso) es precisamente el de una tradición artúrica que en Inglaterra quedase codificado por Spenser en The Fairie Queene (1596), y que alcanza a Tennyson y Browning con indeclinable fuerza. Será precisamente en un ensayo sobre el poema «Childe Roland to the Dark Tower Came» de Browning donde, al hilo de una aclaración del término 
arcaizante «estray», Bloom inserta de manera más clara la errancia existencial del héroe del romance caballeresco en el marco de la errancia irreversible y aporética del lenguaje poético, eso que Paul de Man llamaba aberration:

\footnotetext{
«Estray» is founded on extra + vagare, to wander beyond limits or out of the right way. Roland is an estray, a hyperbolic wanderer, whose dominant trait is extravagance, the Binswangerian Verstiegenheit, the state of having climbed to a height from which one cannot descend safely (Bloom, 1975b: 110).
}

Idéntico extravío condicionaba la posición existencial de Tasso, «me peregrino errante» (Gerusalemme liberata, I.4), proyectada en la silueta de aquellos que «combatton fuggendo erranti e sparsi»(I.50). E idéntico extravío aflige al Satán miltoniano y a sus personajes asociados, como Mulciber, oscuro arquetipo del artista, incluido, recuerda Bloom, el poeta épico, cuya caída («he fell») es narrada en Paradise Lost paralelamente al extravío - «the devastating "Erring" of line 747 is a smack at Homer by way of the errant of Lucretius (De rerum natura, I, 393)» (1975b: 140)- de sus fabuladores. Yerran los héroes y yerran los fabuladores, y del yerro de los fabuladores (Homero, Virgilio, Lucano, Ovidio, Dante, Malory, Tasso, Spenser, Milton) brota la necesidad del contra-yerro catastrófico que es toda narración heroica. Para Bloom, la especificidad de la poesía alto-romántica inglesa y su progenie tardoromántica y modernista (Browning, Hardy, Tennyson, Yeats, Stevens) reside en la brusca interiorización psicológica del romance caballeresco que se inició con Spenser, se retorció moralmente con Milton, y se reactivó de manera tan intensa como anómala en Blake y la épica confesional romántica de Wordsworth, Shelley y Keats. Lo expresa claramente en un ensayo temprano sobre Milton: «Spenser began the internalization of quest-romance that is or became what we call Romanticism» (Bloom, 1975b: 129). En la literatura española, esta interiorización tuvo lugar de manera temprana, en la escritura confesional de Santa Teresa. Pero luego aconteció el Quijote, un texto que cabría describir como exteriorización abortiva del quest-romance. La ausencia, en las literaturas hispanas, de un alto-romanticismo visionario y psicológico comparable al de Blake, Wordsworth o Hölderlin, podría así atribuirse en parte al efecto anulador que el Quijote tuvo sobre la disponibilidad psicológico-existencial del formato heroicocaballeresco: al satíricamente poner al hidalgo como caballero, Cervantes indispuso al caballero para el neo-hidalgo del espíritu que será el poeta romántico. En Inglaterra, en cambio, escritores como Milton, Blake, y sus herederos románticos y modernistas, sí pudieron adaptar el paradigma caballeresco a sus necesidades expresivas de disidencia emocional y rebeldía moral. Hay como una paradoja sangrante en todo esto: al hacer coincidir en el Quijote la ambición psicológica y la sátira realista, Cervantes neutraliza la disponibilidad romántica de la primera. 
Ahora bien, ello no debe hacernos olvidar que la novela cervantina está atravesada y dinamizada por una inquebrantable ambición de gloria, que es escasamente cristiana, que es clásica, es romana, es pagana. En rigor, el Quijote constituye, si descontamos los Evangelios, la primera escenificación realista y narrativa, es decir, psicológicamente libre, no mermada por el alegorismo, de una ambición desmedida (sacrificial) de gloria heroica. En la Gerusalemme o The Fairie Queene esa ambición se da por supuesta, pero la realidad está amortiguada por la idealización del romance y la ambición no constituye el objeto del texto. En Milton esa ambición (la de Satán) se convierte en el centro del poema, pero el escenario está lejos de ser real o, en términos de Frye, «low-mimetic». Don Quijote, en cambio, es un estudio realista sobre la ambición: la voluntad de ser más, el asunto principal, según Bloom, de la poesía alto-romántica. Ahora bien, en los estudios de Bloom, la interiorización del romance heroico que se produce en la poesía alto-romántica inglesa se describe siempre como deficiente, pues el objetivo del poeta romántico, conquistar anterioridad, originalidad y potencia (autoridad), se ve siempre frustrado por limitaciones múltiples ${ }^{6}$. A veces dicha frustración se consigna con tintes patéticos, casi satíricos. De ahí lo que podríamos llamar el momento quijotesco de la poesía fuerte alto-romántico inglesa: la consignación anticipada en forma de ansiedad de la derrota inevitable del yo (Adonis, Satan, Sardanápalo, Prometeo) frente a eso que Bloom llama a aveces anagké, necesidad, y otras veces oscuridad experiencial («experiential darkness»). Quizás el único de los poetas ingleses que logra algo así como una victoria provisional es Milton, el paradigma, para Bloom, del autor:

Our weak moment dallies with the false surmise of the death of the author, a dallying that is outfaced by the scandal of Milton's continued authority, his permanent usurpation of the dialectics of both literary augmentation and authorial resentment (1987: 92).

Bloom describe el poder miltoniano como «potentia, strength, poetic power proper» (91), y opone esta energía psíquica al raquitismo hermenéutico de la que llama «School of Resentment». Así, el titanismo psicológico o heroísmo visionario que luego acabará descubriendo en el Quijote no es más que una confirmación de la potencia literaria, inderrotable por sectarismos críticos y modas, de la energía que Bloom atribuye originalmente a Milton, una energía que éste, a su vez, hurta y sublima de Spenser y Dante, quienes a su vez la usurpan de Virgilio, Homero y la Biblia. Al defender el heroísmo visionario del Quijote, Bloom no hace sino defender a Satán, el personaje miltoniano que ostensiblemente representa a su autor. Ambos, Milton y Satán, son descritos por Bloom como «vitalistas heroicos» (99) animados por la «auto-estima» (101) que persiguen afirmar su autoridad, es decir, su «prioridad» (97), su coraje,

\footnotetext{
${ }^{6}$ Véase especialmente: Harold Bloom. The Visionary Company. A Reading of English Romantic Poetry. (1961: 1-3); «The Internalization of Quest-Romance» Romanticism and Consciousness. Essays in Criticism (1970: 3-24).
} 
«nietzscheano» (103), asegura Bloom, para mentirle al tiempo e imponer tanto su anterioridad como su indestructibilidad. Recordemos la definición: «A poem is a poet's melancholy at his lack of priority» (Bloom 1973: 96). Los versos que registran esta voluntad de permanencia («And courage never to submit nor yield: / And what is else not to be overcome») proceden, según Bloom, de Tasso, lo cual certifica aún mejor la deuda heroico-caballeresca del psico-drama (la gigantomaquia) moral protestante y/o romántico: «We lost the field, yet lost we not our heart». Este orgullo de agónica permanencia sellará asimismo el destino de un «Cervantine egoism» (1994: 134) transferido a su héroe hasta límites insoportables. Para Bloom, la ventaja de Milton es que jamás oculta sus cartas: hay que ser muy obtuso para no leer Paradise Lost como un ejercicio, y poco más, en «poetic authority» (1987: 106). Tratar de reducir a Blake, Wordsworth, Shelley o Keats a meros cronistas de su propia génesis autorial (no necesariamente subjetiva), es decir, a fabuladores más o menos alegóricos de la narración que relata el elevamiento de un autor primero y potente (un strong poet) desde las cenizas de su yo experiencial, es algo más perverso, pero es precisamente lo que había hecho Bloom en sus tres primero libros. Ello le permite, entre otras cosas, distanciarse del patologismo biografista que, en el caso de Blake, provocaba efectos similares a los que Bloom encontrará en la exégesis quijotesca:

Neither [of Blake's nearest ancestors, Christopher Smart and William Collins] attained to the power of Blake's self-knowledge and both went mad in their despairing efforts to express the burden of their struggle with the Spectre within them. That Blake should ever have been considered insane is one of the genuine ironies of literary history, for no poet has ever understood so well what there was within him that might threaten his sanity, and no poet has ever struggled so powerfully to overcome his own morbidity (1963: 375).

Agonismo, lucha, auto-conciencia, supervivencia: este párrafo anticipa claramente el signo de la lectura cervantina de Bloom. Y no olvidemos que se incrusta en un capítulo del extenso estudio del entonces jovencísimo crítico norteamericano dedicado a explorar la inflexión épica, un romance revival que en el caso de Blake negocia casi exclusivamente con el Antiguo Testamento y Milton, del poema Jerusalem, en el que la caída Albión, con el fin de edificar la nueva Jerusalem, tiene que derrotar a los molinos satánicos -«Satanic mills» (1963: 383)- de la educación científica la incipiente razón industrial. El motivo, ya no nos sorprende, es en sí mismo genuinamente quijotesco.

Y esto explica la pirueta: Bloom no vuelve romántico al Quijote por capricho, sino porque, para él, lo romántico es ya de por sí un horizonte atravesado de quijotismo, es decir, penetrado de heroísmo derrotado y/o autoridad minada. De ahí que, en el ensayo de Bloom sobre el Quijote, se produzca una correlación necesaria entre las nociones de «indestructibility» (1994: 138), «heroic persistence» (144) y, finalmente, «pride of authorship» (131). Dicha correlación nos permite comprender que el asunto 
determinante de la poética bloomeana, el tema de la fuerza como autoridad que se pretende auto-generación inscriptora, el asunto de la supervivencia de la gloria literaria, entendida como usurpación axiológica de una violencia primaria empeñada en perpetuarse en la restauración interesada de genealogías con el fin de obtener prioridad y originalidad, es un asunto sospechosamente paralelo al de la fuerza en el plano de la acción heroica, programada para perpetuarse en la economía cultural de la fama y la reputación.

Esto es importante porque al sujeto y súbdito Miguel de Cervantes le cupo el raro honor de lidiar en ambas plazas: participó tanto una suerte de victoriosa cruzada colectiva contra el turco (Lepanto) -que reinscribía tanto cruzadas reales como la narrada por Tasso- como en una aparentemente desastrosa cruzada personal contra el olvido literario. Se ha dicho muchas veces pero conviene repetirlo: en un sentido estricto, Cervantes fue un autor fracasado. Al no cosechar triunfos en la tragedia, al no pretenderlos en la épica, y al no obtener espacio suficiente en el horizonte saturado de la comedia (saturado, claro, por el nombre de Lope), Cervantes tuvo que desplazarse a la posición insólita de publicar sus comedias y escribir novelas. En este sentido, Cervantes es un nombre que se desplaza por la geografía limitada del campo literario tratando de buscar una posición de potencia, un sitio de autoridad. Esto, insisto, ya se ha señalado muchas veces. Lo que conviene añadir es que el nombre se desplaza porque ya estaba en marcha, ya había sido movilizado anteriormente para otro juego: el juego de la guerra. No es de extrañar, por ello, que en la obra que es testimonio de su fracaso (Don Quijote), asistamos a una doble conmutación de energía heroica: la fuerza militar se transforma en una energía literaria que, renuente a camuflar su origen, se pone en juego como re-potenciación militar. Estamos ante un problema de mecánica elemental, un asunto de energía que no se destruye, sino que se transforma. Pero precisamente en la rara medida en que esta energía sí se crea, sí se inscribe inicialmente como autorización originaria de potencia, la transformación de la energía deviene perversamente, anómalamente, auto-alusiva. La mecánica es elemental, pero defectuosa. Sabemos que Alejandro Magno estaba obsesionado con Aquiles, y sabemos que Julio César lloró de impotencia en Cádiz ante una estatua de Alejandro Magno. Sabemos también, y esto es lo decisivo, que Aquiles ni estaba obsesionado ni lloraba: hijo de una Nereida, tocado por la gracia divina del origen, Aquiles estaba sencillamente hastiado de su propia fuerza. Inscribirse como inmortal en el juego del heroísmo occidental -algo que pretendieron muchos, desde Carlos V hasta Napoleón- ha consistido siempre en reinscribir a Aquiles. En el juego literario las cosas fueron inicialmente muy claras: la inscripción de autoridad consistía en la correcta reinscripción de la originaria narración de la epopeya de Aquiles, la Ilíada. Pero luego, pese a la tozuda supervivencia de la normativa neoclásica, el juego se fue fracturando en ámbitos de litigio y agonismo 
alternativos: una tropología decididamente epigonal y derivativa (centrada en la ironía y figuras asociadas) permitió un mecanismo alternativo de reinscripción de energía contra-heroica o para-heroica. Quedaría así trazado, como sugiere Bloom en El canon occidental, el mundo secular, cómico, y escéptico de Montaigne, Shakespeare y Cervantes. Dicho mundo marcaría el límite cronológico tras el cual sobrevendría, según Bloom, el diluvio de la ansiedad epigonal, del que solamente se salvaría el escritor inglés: «Shakespeare belongs to the giant age before the flood, before the anxiety of influence became central to poetic consciousness» (1973: 11). ¿Podemos decir lo mismo de Cervantes? Obviamente, no.

Con Cervantes ingresamos de lleno en un ámbito de impostura, ansiedad y simulación, un horizonte para la ingeniería de usurpaciones del comienzo, de reconducciones de las fuentes (reales o literarias) de la fuerza heroica. Cascardy recuerda con pertinencia la reprobación de Erasmo en La educación del príncipe cristiano contra la incitación al comportamiento tiránico que se aloja en algunos narraciones que describen las hazañas de Aquiles, Alejandro Magno, Jerjes o Julio César (21). Evidentemente, dicha reprobación es literal. Pero qué decir de la apostilla exculpatoria que añade el cura al riguroso juicio que el canónigo de Toledo emite sobre los libros de caballería. Para el cura, el sujeto o tema de dichos libros ofrece un espacio de ejercitación al entendimiento del lector:

Puede mostrar las astucias de Ulixes, la piedad de Eneas, la valentía de Aquiles, las desgracias de Héctor, las traiciones de Simón, la amistad de Eurialio, la liberalidad de Alejandro, el valor de César, la clemencia y verdad de Trajano, la fidelidad de Zópiro, la prudencia de Catón, y, finalmente, todas aquellas acciones que pueden hacer perfecto a un varón ilustre (Don Quijote, I, 47, 1605: 550).

En la trama de este inventario se dibuja la genealogía que importa: Aquiles, Alejandro, César. Pero, pese a su dignísimo comportamiento en Lepanto, ni Miguel de Cervantes ni su jefe Juan de Austria pueden ya ser Aquiles. Ni siquiera Garcilaso, también soldado heroico, puede aspirar a un puesto en ese linaje privilegiado. Garcilaso se perpetuó, en cambio, como príncipe o princeps, es decir, primero de los poetas españoles. Y Cervantes aspira a esa prioridad. Como afirmaba un interlocutor del diálogo de Tasso sobre la nobleza: «Già mi pare che tre sorti d'uomini abbiamo ritrovate, a le quale si conviene l'illustre: e queste sono i principi, i gran capitani e i gran poeti» (Tasso, 1581b: 174). Desde su regreso del cautiverio de Argel, Cervantes se despide del juego de la guerra. Necesita, en primer lugar, reaprender a vivir, igual que el soldado que regresa a Lisboa, en la excelente novela de Lobo Antunes, procedente de la guerra de Angola:

Se me ocurría que cuando llegase por radio la noticia del alta nos haría falta un penoso reaprendizaje de la vida, a la manera de los hemipléjicos que ejercitan el difícil y 
cimbreante espagueti de los miembros en aparatos y piscinas, y que tal vez seríamos para siempre incapaces de andar, reducidos a la silla de ruedas de una resignación paralítica, observando la sencillez de lo cotidiano como el Chaplin de Tiempos modernos observa las máquinas pavorosas que implacablemente lo trituran (Lobo Antunes, 1979: 54).

Esta descripción se ajusta poderosamente a la triste y raquítica figura del hidalgo de rocín flaco y lanza rota, maltrecho por la estocada mecánica de una gigantesca aspa de molino. Ni Cervantes ni su criatura obtuvieron satisfacción en el reaprendizaje de sus vidas. Tras el juego de la guerra y el fracaso de la vida, Cervantes se esforzó por encontrar una alternativa al juego literario neoclásico que monopolizaba la producción de la fuerza de la escritura, sus mecanismos de crédito y autorización. En Tasso, Shakespeare y Cervantes el neoclasicismo alcanza un límite de presión interna desconocido. Tasso se mantiene, a costa quizás de su salud mental: el poeta gana autoridad a medida que la persona la pierde. Los autores Shakespeare y Cervantes, en cambio, estallan. Shakespeare lo desdibuja todo en una profunda intensidad anómica, evocadora sin embargo de los límites perdidos (comedia, tragedia...). Cervantes produce otro juego: la novela. Como luego sucede en su heredero Fielding, él solo se autoproclama juez y árbitro de aquello que suceda en esa nueva provincia de escritura. Pero ello no implica que el nuevo juego no tenga relación con los anteriores: el Quijote versa sobre la autorización y autoridad de la fuerza, en sus tres variantes epocales: la fuerza militar (heroísmo aristocrático), la fuerza literaria (fama) y sobre la fuerza del mercado (el oro de la incipiente burguesía).

Pero el texto que mejor escenifica las condiciones de esta recanalización de la autoridad, de esta reconducción de la fuerza, es sin duda el Laurel de Apolo (1630) de Lope de Vega, crónica o memorial de lo sucedido en las Cortes convocadas por la Fama en el Parnaso, «para que a ellas viniesen los pretendientes de mayores méritos» («Dedicatoria», 1630: 116). En este poema alegórico se manifiesta con nitidez la perpetuación del juego militar en la forma de una justa valorativa. La finalidad explícita del nuevo juego es clara: obtener fuerza -autoridad, honor, distinción, reconocimiento: reputación, dirían Gracián y Hobbes- en un ámbito agonístico de competición (competidor y opositor son términos muy usado por Lope) presidido por la fuerza de la inventio. La finalidad implícita es obtener crédito social, un caudal axiológico sólo accesible mediante la atribución ajena de reputación propia, venga dicha reputación de donde venga. Para Thomas Hobbes, el filósofo que mejor explica la escritura cervantina, «reputation of power is power» (1651: 150). No en vano fue Hobbes un cuidadoso lector de Gracián, y no sólo del Criticón, sino también de El Héroe, un decisivo tratado que dialoga con el Quijote de manera tan íntima como indirecta ${ }^{7}$. Pero

\footnotetext{
${ }^{7}$ Para la deuda de Hobbes con Gracián, véase el primer capítulo del libro de Yves Charles Zarka, Hobbes et le pensée politique moderne (1995).
} 
volvamos a Lope. El Laurel de Apolo ofrece cuatro horizontes figurales para expresar la reconducción diversificada de la fuerza. El primero es la imagen cósmica del sol, como generador universal. El segundo es el oro y sus variantes menores (plata, piedras preciosas, minerales), que designan el plano creciente del mercado. El tercero es la fuerza militar, espacio genuino y originario de autoridad. Y el cuarto, el que domina la acción del poema, es el ámbito la fuerza de la creación, del ingenio, que rotura el campo de las letras. Estamos ante cuatro fuentes de autoría, autoridad y autorización. Para Lope, las dos únicas fuentes que interesan son las del mercado y la literatura. De hecho, si Lope vence a Cervantes no es sólo por la mayor autoridad de su invención dramática. Lope vence porque supo comprender que ambos ámbitos, el mercantil y el literario, constituían un solo campo de actuación.

En el Laurel, los méritos literarios se confunden con los militares, quedando ambos sancionados por el crédito mitológico (sol, Febo, laurel, Apolo) y a ello se superpone, constantemente, decisivamente, con tranquila obstinación, el oro y plata americanos, insinuando un régimen de acreditación diverso. Para un afligido recaudador de impuestos como Cervantes, escéptico por más señas del imperialismo hispano, dicha acreditación alternativa podía provocar una incomodidad insalvable ${ }^{8}$. Pero Lope sabía que el único modo de poner entre paréntesis el orden de acreditación política que regulaba la asignación de autoridad y prestigio en el marco de la nueva burocracia imperial era mediante la invocación de otro orden crediticio totalmente reconciliado con la nueva axiología del mercado. Suspenso el orden burocrático-político, trascendido totalmente el orden heroico (cimiento legendario del orden estamental), el único régimen visible era el de la «poesistocracia»:

Veréis como difusas
los ingenios laurean,
que las cumbres difíciles pasean
de Pimpla y de Bibetro,
que se propone el siempre verde cetro
de Dafnes, aun ingrata en tierna rama,
a quien España «Proto-Apolo» llama,
materia digna de mayor sujeto
y de la envidia más heroico objeto;
que no quisiera ver monarca alguno,
sino que todo cuanto España oyera
poesistocracia fuera (I, 82-93).

Antonio Carreño, en su edición del poema, anota el término poesistocracia como «neologismo por 'poesía refinada, elegante, aristocrática'» (2007: 139). Me parece que se equivoca, pues el sentido de poesistocracia debe acomodarse analógicamente al de

\footnotetext{
${ }^{8}$ En su excelente estudio biográfico sobre Cervantes, Javier Blasco subraya la animosidad anti-imperial del escritor. Véase, en especial el capítulo XVII, «Comisario de abastos y recaudador de impuestos» en Cervantes. Un hombre que escribe (2006: 241-263).
} 
otros términos afines, como democracia, aristocracia o sacarocracia, y así significar «poder de la poesía». Trocada, pues, en poesistocracia, España no sólo deviene «de la envidia más heroico objeto», sino que queda animada internamente por una economía de la envidia literaria. El propio Don Quijote reconocía que «no hay poeta que no sea arrogante y piense en sí que es el mayor poeta del mundo» (II, 18). El mayor poeta, el primer poeta, el príncipe de la poesistocracia. Cervantes comprendió pronto que no lo era, y desplazó parte de su autoridad destituida al ámbito sucedáneo del arbitraje. Con ello pretendía blindar el campo crediticio de una nueva exposición axiológica, facilitar eso que Pedro Ruiz denomina «la definitiva afirmación de la autonomía de la poesía para construir su discurso sin referentes externos que garanticen su ennoblecimiento» (Ruiz Pérez, 2006: 21). Pero no lo logró. En la medida el Viaje al Parnaso constituye un ejercicio de «autobiographical self-recognition»(Bloom, 1970: 63), la frustración ante la carencia de una nobleza (virtud, nombre, fuerza, gracia) innata contamina el texto de una colosal referencia externa (el yo cervantino) y resquebraja su autonomía. Con enorme perspicacia sociológica, Pedro Ruiz proponen las claves que determinan el intento semi-fracasado de Cervantes por «alcanzar una posición» en el ámbito de las letras, paralelo, en el fondo, al de su hidalgo por ponerse y reponerse sucesivamente en el ámbito, fantasmagórico y brutal, de las armas:

Sin nobleza de cuna ni sólida formación letrada, Cervantes cubre su etapa de soldado de infantería a sueldo, tras unos primeros ensayos de salida pública de su verso en marco, circunstancias y cauce representativos del desplazamiento de lo cortesano sensu stricto a los espacios académicos y urbanos; esto es, al empuñar tanto el arcabuz como la pluma nuestro autor, como muchos otros de su promoción, están atendiendo menos, respectivamente, a la obligación de la sangre o al ocio y la eutrapelia que a la búsqueda de un modus vivendi; como las armas, las letras no son ya el adorno del caballero, a modo de corolario insoslayable de su posición social, sino la base para alcanzar una posición en una sociedad a la que acceden desde los márgenes, cuando no han quedado directamente excluidos de espacio de luz. Y no sólo han cambiado los personajes: también lo ha hecho el escenario, ya que entre ambos extremos de gloria, las cúspides de la corte y del parnaso, apenas queda el estrecho y poco brillante reducto del servicio, en particular el de las covachuelas y tareas administrativas y de intendencia del gobierno del rey papelero, reverso del un tanto anacrónico ideal de su hermanastro Juan de Austria, vencedor en Lepanto y objeto de la celebración de La Austriada, epopeya real y epopeya en verso, batalla e impreso, donde Cervantes tendría un cierto protagonismo y su pequeño momento de gloria. En semejante marco de transición, antes de un modelo social que de una proyección estética, se resuelven algunas de las opciones (si no determinaciones) de Cervantes en relación con las letras y, en particular, con el cultivo de la poesía (Ruiz Pérez, 2011: 162).

Tras La Araucana y La Austríada, la destitución progresiva de la enunciación épica en suelo hispano se hará crónica. Señalados vates, como Lope, se reorientaron hacia el mock-epic, mientras que otros, como Cervantes, limitaron su máxima ambición literaria a la tragedia, con resultado incierto. Diremos, con Bloom que tras la inundación (anti-neoclásica) le tocó el turno a la crítica epigonal, y la poesía reanimó su tendencia latente a degenerar en crónica auto-alusiva, apología y canon personal. En efecto, lo que 
Lope, autor y árbitro, hiciera en el Laurel, Cervantes ya lo había hecho en su excepcional Viaje del Parnaso. Ambos poemas son ejercicios de arbitraje, es decir, escrutinios, realizados en el ámbito virtual de la poesistocracia. Al final del Capítulo primero del Viaje, Mercurio saca una lista:

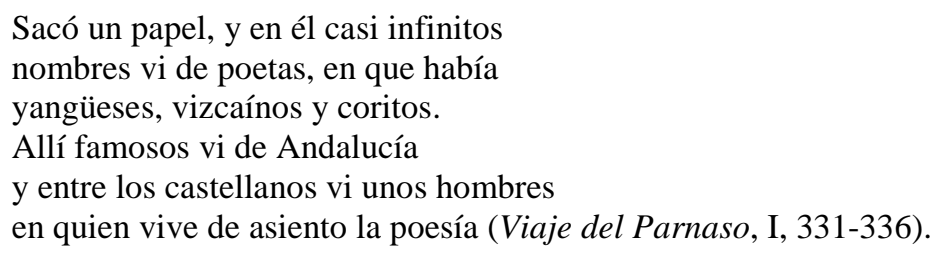

Y el meollo descriptivo del poema arranca tras una ojeada al inventario -«Miré la lista»- que abre el siguiente capítulo. Pero ¿se puede escribir un poema sobre una lista? ¿Se puede articular un poema alegórico en torno a un listado de los mejores poetas contemporáneos? Parece raro, pero Cervantes lo hizo, con humor, sin duda, aunque también con la arrogancia herida, desplazado a una insólita posición de arbitraje. Y luego lo hizo Lope. Y Tasso había hecho algo parecido en su diálogo «La Cavaletta overo de la poesia toscana» (1587), y algo similar hizo Sidney en la parte final de su Defence of Poesy (1595). ¿Por qué, entonces, orquestar un absurdo debate crítico sobre la oportunidad de una lista de los mejores escritores realizada por un crítico norteamericano en 1994? ¿Acaso la literatura es en realidad mucho más que un epifenómeno estético que persigue por todos sus medios sublimar su contingencia agonística, su economía de pugilato, su posición de conflicto desplazado, de juego normativo (canon) imantado hacia la autoridad y regulado por el arbitraje? ¿Acaso no dramatiza el texto literario, ora explícita ora implícitamente, el arbitraje saboteador y receloso de la norma o canon que lo autoriza?

Harold Bloom sacó un buen día un papel, igual que lo sacaron Lope y Cervantes, de manera equivalente, en el fondo, al verso que se sacó Dante siglos atrás, cuando solicitó a su amigo Cavalcanti «Guido, i’ vorrei che tu e Lapo ed io / fossimo presi per incantamento / e messi in un vasel ch'ad ogni vento / per mare andasse al voler vostro e mio» (Alighieri, "Soneto 9 [LII]", 1995: 35) para de este modo elevarse a las altas esferas de la comunidad poesistocrática. En su canon, Bloom se dio una vuelta aerostática con Dante, Cervantes, Shakespeare, Milton y otros, aunque lo que probablemente le pedía el cuerpo, como a Dante, era amablemente conversar con amigos, en su caso A. R. Ammons o Philip Roth, incluidos en la lista. Que se desengañe quien lo necesite: hacer crítica consiste en arbitrar, en distinguir, en virtud de una subjetividad más o menos disfrazada de objetividad, lo bueno de lo malo, y lo bueno de lo mejor. La lista será implícita o explícita, pero será. Bloom redactó subjetivamente un puñado de sugerentes ensayos en torno a una minoría selecta de autores occidentales, y 
luego le añadió un papel, una lista, sin duda por motivos editoriales. Que no renunciara a elaborar esa lista denota paciencia y olfato comercial, pero es también un ejercicio de responsabilidad con la tarea natural del crítico que da la cara. También puso sus listas, sus escrutinios más o menos normativos, más o menos irónicos, de curas, de barberos y canónigos, Cervantes en su Quijote, en su novela que es también un canon, como lo es toda inscripción que, traficando con genealogías, persigue simular (usurpar) su propio origen. «What the Canon said» es el título de un capítulo del libro de Cascardy, y lo cierto es que a Bloom, enemigo de la «secular clergy» (1987: 93) de la universidad norteamericana, probablemente no le importase figurar en la novela como canónigo (canon, en inglés), cura, barbero o como el mismísimo Sancho Panza. Lo que le importa es que sigamos escrutando what his canon said, pues ello revela el signo de su indiscutible originalidad. Autoridad y/o arbitraje, autoridad como arbitraje, todo se reduce en el fondo a una cuestión de poder. En 1982, doce años antes de la publicación de su canon, escribía Bloom un párrafo memorable, premonitorio de lo que luego esbozó sobre el Quijote:

The power I seek to gain over the text is what Milton's Satan called 'quickening power', the conviction of pragmatic self-engendering. Such a power is parallel to any strong poem's power over its precursor poems. Power, in this sense, is neither the autonomous ego's location of itself in history, as in Abrams, nor the deconstructive process's demystification both of the ego and of history, as in Derrida. The irony of the selfhood in history, and the irony of linguistic enclosure, differ at last only as degrees of irony. Self and language alike are ironies, saying one thing or something, while meaning another or nothing. What concerns me in a strong poem is neither self nor language but the utterance, within a tradition of uttering, of the image or lie of voice, where 'voice' is neither self nor language, but rather spark or pneuma as opposed to self, and act made one with word (davhar) rather than word referring only to another word (logos). A poem is a spark and act, or else we need not read it a second time. Criticism is spark and act, or else we need not read it at all (1982a: 3-4).

Cervantes se lamentaba en el Viaje del Parnaso de la gracia que no supo darle el cielo. Esa gracia es la potencia de la utterance o enunciación (épica, trágica, lírica), aquella que permite la acción de aliento (voice, pneuma) que percute y repercute como detonación en el aire. Don Quijote brota así como un esfuerzo de resignación, un ejercicio de extravagancia en el que las ironías paralelas del yo y del lenguaje dibujan trayectorias de comunión improbable. Aunque en calidad de ejecución crítica, la novela de Cervantes permanece efectivamente como acción. «The revisionist commits many errors in searching for an individual relation to truth, but some of those errors become the true history of strong poetry», asegura Bloom en Kabbalah and Criticism (1975a: 92), y en ese sentido preciso cabe leer el Quijote como un error colosal en la verdadera historia de la poesía fuerte, de la poesía con poder, aliento y fuerza, la poesía, en definitiva, que ya no era posible escribir, en español al menos, a partir de 1600. 
Asegura Gracián en El Héroe que «gran ventaja el ser primero, y si con eminencia, doblada». Y luego añade: «Son multiplicados los caminos que llevan a la singularidad, no todos sendereados [...] Extiéndese el ejemplo a todo empleo, y todo varón raro entienda bien la treta, que en la eminente novedad sabrá hallar extravagante rumbo para la grandeza" (Gracián, 1637: 61-62). Varón raro extravagante por caminos no sendereados: exacta definición del caballero.

\section{Referencias Bibliográficas}

ALIGHIERI, D. (1995): Rime. Ed de. G.Contini. Torino, Einaudi.

BLASCO, J. (2006): Cervantes. Un hombre que escribe. Valladolid, Difícil.

BLOOM, H. (1959): Shelley's Mythmaking. Ithaca, Cornell University Press.

- (1961): The Visionary Company. A Reading of English Romantic Poetry. Ithaca, Cornell University Press.

- (1963): Blake's Apocalypse. A Study in Poetic Argument. Ithaca, Cornell University Press.

- (1969): «The Internalization of Quest-Romance», en Romanticism and Consciousness. Essays in Criticism. Ed. Harold Bloom. New York, Norton, 1970, pp. 3-24.

(1970): Yeats. Oxford, Oxford University Press.

- (1973): The Anxiety of Influence. A Theory of Poetry. Oxford, Oxford University Press.

- (1975a): Kabbalah and Criticism. New York, Continuum, 1993.

(1975b): A Map of Misreading. Oxford, Oxford University Press.

- (1976): Poetry and Repression. Revisionism from Blake to Stevens. New Haven, Yale University Press.

- (1982a): The Breaking of the Vessels. Chicago, The University of Chicago Press. (1982b): Agon. Towards a Theory of Revisionism. Oxford, Oxford University Press.

(1987): Ruin the Sacred Truths. Poetry and Belief from the Bible to the Present. Cambridge (Mass.), Harvard University Press.

(1994): The Western Canon. The Books and School of the Ages. New York, Harcourt Brace \& Company.

CASCARDY, A. (2012): Cervantes, Literature, and the Discourse of Politics. Toronto, University of Toronto Press.

CERVANTES, M. (1605/1615): Don Quijote de la Mancha. Ed. Francisco Rico. Barcelona, Crítica, 1998.

(1614): Viaje del Parnaso. Ed. Vicente Gaos. Madrid, Castalia, 1973. 
DERRIDA, J. (1967): L'écriture et la différence. Paris, Seuil.

FOUCAULT, M. (1966): Les mots et les choses. Une archéologie des sciences humaines. Paris, Gallimard.

GRACIÁN, B. (1637): El héroe. Ed. Agustín Izquierdo. Madrid, Edaf, 2009.

HOBBES, T. (1651): Leviathan. Ed. James Macpherson. London, Penguin, 1968.

LACLAU, E. \& MOUFFE, C. (1985): Hegemony and Socialist Strategy. Towards a Radical Democratic Politics. London, Verso, 2a ed., 2001.

LOBO ANTUNES, A. (1979): En el culo del mundo. Trad. Mario Merlino. Barcelona, Mondadori, 2012.

MAN, P. de (1979): Allegories of Reading. New Haven, Yale University Press.

NABOKOV, V. (1941): Lectures on Don Quixote. Ed. Fredson Bowers. New York, Harcourt Brace, 1983.

(1967): Speak Memory. An Autobiography Revisited. New York, Penguin, 2001.

NIETZSCHE, F. (1992): Zur Genealogie der Moral. Berlin, Goldmann Verlag.

DE RIQUER, M. (1967): Caballeros andantes españoles. Madrid, Espasa-Calpe.

QUEVEDO, F. (1628): La Vida del Buscón. Ed. Fernando Cabo. Barcelona, Crítica, 1993.

SAID, E. (1975): Begninnings. Intention and Method. London, Granta, 1985.

RODRÍGUEZ, J. C. (1994): La literatura del pobre. Granada, Comares.

RUIZ PÉREZ, P. (2006): «Contexto crítico de la poesía cervantina», en La distinción cervantina. Poética e historia. Alcala de Henares, Centro de Estudios Cervantinos, pp. 15-36.

(2011): «Cervantes y la poesía», en F. Sevilla Arroyo, ed., Retrato de Miguel de Cervantes. Guanajuato, Universidad de Guanajuato, pp. 157-204.

TASSO, T. (1581a): Gerusalemme liberata. Ed. M. Guglielminetti. Milano, Garzanti, 1982.

(1581b): «Il Forno overo de la nobiltà», en Dialoghi. Ed. Giovanni Baffetti. Milano: Rizzoli, vol I, 1998.

DE VEGA, L. (1630): Laurel de Apolo. Ed. Antonio Carreño. Madrid, Cátedra, 2007.

WEIL, S. (1940): War and the Iliad. Trad. Mary McCarthy. New York, New York Review Books, 2005.

ZARKA, Y. C. (1995): Hobbes et le pensée politique moderne. Paris, Presses Universitaires de France. 